\section{Off-season Production of Primocane- fruiting Red Raspberry Using Summer Pruning and Polyethylene Tunnels}

\author{
Pedro B. Oliveira ${ }^{1}$ and Cristina M. Oliveira ${ }^{2}$ \\ Instituto Superior de Agronomia, Universidade Técnica de Lisboa, Tapada da \\ Ajuda, 1399 Lisboa, Portugal \\ Luís Lopes-da-Fonseca ${ }^{3}$ \\ Estação Nacional de Fruticultura Vieira da Natividade, Instituto Nacional de \\ Investigação Agrária, 2460 Alcobaça, Portugal
}

\author{
António A. Monteiro ${ }^{4}$ \\ Instituto Superior de Agronomia, Universidade Técnica de Lisboa, Tapada da \\ Ajuda, 1399 Lisboa, Portugal
}

Additional index words. Rubus idaeus, photosynthetic productivity, fruit quality

\begin{abstract}
The spring shoots of 'Autumn Bliss' red raspberry (Rubus idaeus L. var. idaeus; primocane-fruiting type) were cut on 2, 16, 31 July and 15 and 30 Aug. with the objective of delaying fruit harvest into the off-season under mild winter climatic conditions. Cutting shoots in August delayed fruit harvest until February and April of the following year, but shoot growth was weak and fruit yield low (4.8 and $2.1 \mathrm{~g} /$ cane). July cuttings delayed harvest until October to January with acceptable fruit yield $(63.5,52.8$, and $26.5 \mathrm{~g} / \mathrm{cane}$ for 2,16 , and 31 July, respectively). The differences in cane height and total node and fruiting node count between the three cutting dates of July were small, but there was a constant decrease in leaf area per cane from the first to the third date and a sharp decrease in fruit yield from the second to the third date. Vegetative shoot growth was less affected than yield when summer cutting was delayed until the end of July to induce a later harvest. Fruit quality always reached acceptable standards. This study confirms the practicability of using summer-cutting of primocane-fruiting red raspberries to induce off-season fruit production under protected cultivation in mild winter climates.
\end{abstract}

The economic advantage of off-season raspberry production for fresh market led growers to try new techniques for extending the production period. Earlier work on the effects of the environment on Rubus idaeus (Williams, 1959,1960 ) outlined the major physiological processes related to the development of the raspberry plant in diverse environments. Several methods are now available, with various combinations for autumn and summer cultivars, that extend or delay the harvest period. Each production technique must be adapted to a particular region. In northern Europe, researchers developed various technologies using cold-treated canes of summer-fruiting cultivars grown in pots in heated greenhouses

Received for publication 17 July 1995 . Accepted for publication 23 Mar. 1996. We gratefully acknowledge the assistance of Beatriz Sousa in quality analysis of fruit and the statistical assistance of Jorge Cadima. This work was supported by Junta Nacional de Investigaçăo Cientifica e Tecnológica (JNICT), Programa Ciência, Portugal. The cost of publishing this paper was defrayed in part by the payment of page charges. Under postal regulations, this paper therefore must be hereby marked advertisement solely to indicate this fact.

${ }^{1} \mathrm{PhD}$ Student.

${ }^{2}$ Assistant Professor.

${ }^{3}$ Director.

${ }^{4}$ Professor, to whom reprint requests should be addressed. red raspberry.

${ }^{* * *}$ Significant at $P \leq 0.05$ and 0.01 , respectively. tiation can be maintained through September and October. The reduced light intensity and soil and air temperatures that occur during late fall seem to be the most limiting factors for crop productivity. The effects of the reduction in light intensity on yield were reviewed by Dale (1989) and the effects of temperature were studied by Hoover et al. (1989) and Privé et al. (1993) and can be used to interpret raspberry behavior under a particular cropping situation.

Our objective was to quantify the relationship between time of cane cutting, productivity, and quality characteristics of 'Autumn Bliss' raspberry grown in unheated polyethylene tunnels in a mild winter climate.

\section{Materials and Methods}

'Autumn Bliss' primocane-fruiting red raspberries were grown on a sandy soil in a polyethylene-covered tunnel located $500 \mathrm{~m}$ from the sea on the southwest coast of Portugal (lat. $37^{\circ} \mathrm{N}$ ) at $40 \mathrm{~m}$ above sea level under a mild winter climate. The tunnels were $3.5 \mathrm{~m}$ high, 9 $\mathrm{m}$ wide, and $60 \mathrm{~m}$ long and were opened up to $50 \%$ on both sides. Double rows of 'Autumn Bliss' were planted in Feb. 1991. The distance between rows was $1.6 \mathrm{~m}$, and the distance between plants was $0.3 \mathrm{~m}$. Rows were oriented north to south. A traditional "V" supporting system for primocane-fruiting red raspberries was used. Irrigation and fertigation were computer-controlled, and insects and diseases were controlled following local commercial practices.

The crop was planted in February, and from March to July or August the plants were allowed to produce new canes. The five treatments consisted of cutting the canes at ground level at five dates: 2, 16, 31 July and 15 and 30 Aug. A randomized block design with four replications was used. Each plot consisted of three double rows (5.4 m long). The plants were 5 to 6 months old at the time of cutting. Cane density varied from 21 to 32 canes $/ \mathrm{m}$ of row in the first and last cut, respectively. Owing to differences in cane density, 10 stools per plot were randomly selected and treated as experimental units. Cane height, node count, number of fruiting nodes, length of the fruiting section, total dry weight (leaves and canes), and total leaf area were recorded at the end of fruit harvest. Leaf area was measured with a leaf area meter (Mark 2; Delta-T Devices,

Table 1. Effect of summer cutting dates on growth characteristics and fruit yield per cane of 'Autumn Bliss'

\begin{tabular}{|c|c|c|c|c|c|c|}
\hline \multirow{3}{*}{$\begin{array}{l}\text { Cutting } \\
\text { date }\end{array}$} & \multicolumn{5}{|c|}{ Growth characteristics } & \multirow{3}{*}{$\begin{array}{r}\text { Yield/ } \\
\text { cane }(\mathrm{g})\end{array}$} \\
\hline & \multirow{2}{*}{$\begin{array}{l}\text { Cane ht } \\
(\mathrm{cm})\end{array}$} & \multicolumn{2}{|c|}{ Nodes (no.) } & \multirow{2}{*}{$\begin{array}{c}\text { Cane dry } \\
\text { wt (g) }\end{array}$} & \multirow{2}{*}{$\begin{array}{l}\text { Leaf area/ } \\
\text { cane }\left(\mathrm{m}^{2}\right)\end{array}$} & \\
\hline & & Total & Fruiting & & & \\
\hline 2 July & 95.0 & 31.9 & 8.1 & 25.0 & 1.74 & 63.5 \\
\hline 16 July & 95.6 & 32.9 & 8.0 & 20.3 & 1.15 & 52.8 \\
\hline 31 July & 88.0 & 30.0 & 7.7 & 16.4 & 0.99 & 26.5 \\
\hline 15 Aug. & 63.3 & 21.0 & 3.4 & 10.5 & 0.49 & 4.8 \\
\hline 30 Aug. & 57.0 & 18.5 & 2.7 & 8.9 & 0.11 & 2.1 \\
\hline \multicolumn{7}{|l|}{ Significance } \\
\hline Linear & $* *$ & $*$ & $* *$ & $* *$ & $* *$ & ** \\
\hline Quadratic & $* *$ & $* *$ & $* *$ & $* *$ & $* *$ & $* *$ \\
\hline
\end{tabular}




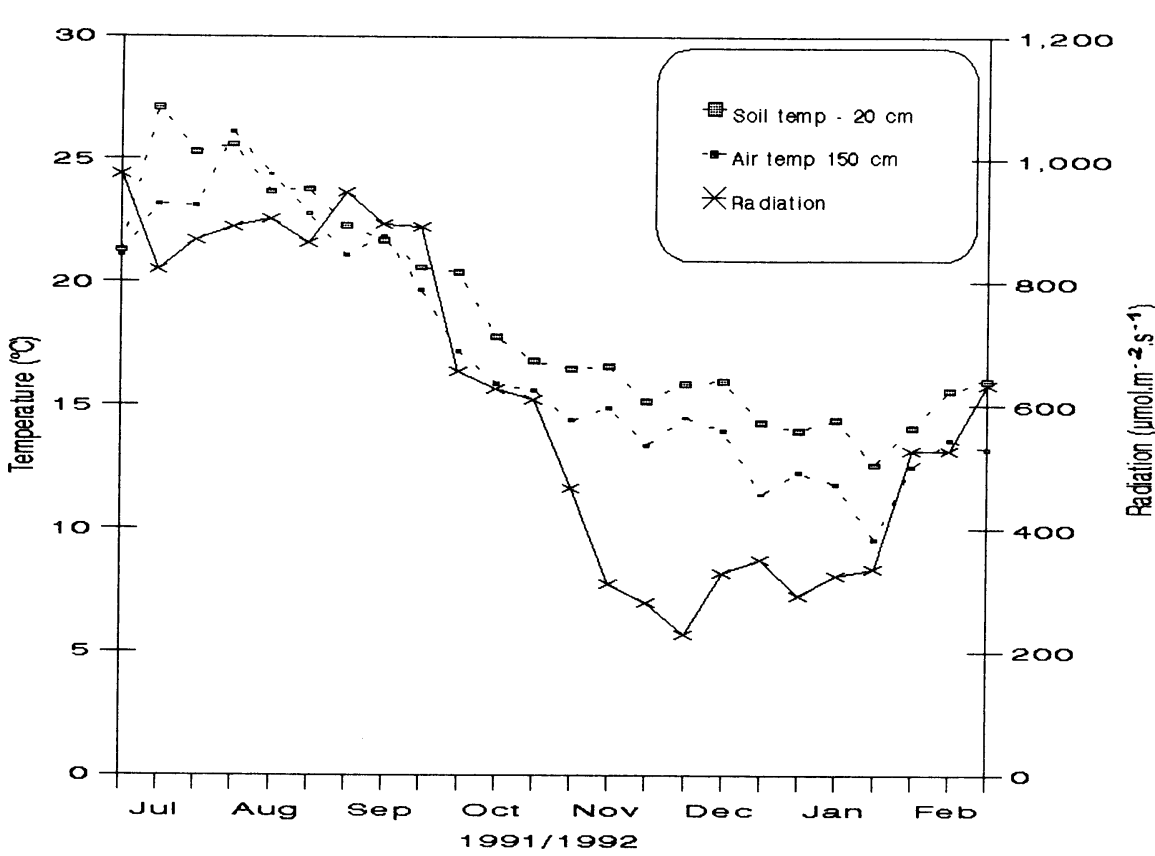

Fig. 1. Soil and air temperatures (in Celsius) and radiation (in micromoles per square meter per second) during the growing cycle of 'Autumn Bliss' red raspberry.

Cambridge, England). Soil temperature at 20 $\mathrm{cm}$ deep, air temperature at $150 \mathrm{~cm}$ aboveground, and photosynthetic active radiation (PAR) inside the tunnel were measured with the appropriate sensors every $10 \mathrm{~s}$. These measurements were averaged hourly and recorded in a datalogger (DL2; Delta-T Devices). Heat units were calculated according to Hoover et al. (1989). Fruit were picked weekly, counted, and weighed. Fruit length, diameter, and weight were measured. The fruit analysis was done on 500-g samples from the second harvest date, which occurred on 28 Nov. for the plants of the first cutting date, on 13 Dec. for the second, and on 16 Jan. for the third. The August cutting dates did not produce enough fruit for a replicated analysis of quality. The color was measured on a 30-fruit sample, using a tristimulus color analyzer (chromameter, CR-200b; Minolta, Osaka, Japan) equipped with a head with a measuring area $8 \mathrm{~mm}$ in diameter. Measurements were recorded in $\mathrm{L}^{*} \mathrm{a}^{*} \mathrm{~b}^{*} \mathrm{CIE}$ coordinates. Fruit $(25$ g) was blended with $100 \mathrm{ml}$ of water, centrifuged, and filtered through a Whatman no. 4 filter paper. Then $10 \mathrm{ml}$ of supernatant was added to $90 \mathrm{ml}$ distilled water and titrated to pH 8.3 with $0.1 \mathrm{~N} \mathrm{NaOH}$. Titratable acidity was calculated as percent (in grams per 100 milliliter) citric acid. The juice $\mathrm{pH}$ was measured with a potentiometer (E/632, Metrohm SA, Herisau, Switzerland). The soluble solids concentration (SSC) was determined by refractometry (Atago PR-1; Atago Co., Tokyo), and the total reducing sugars were determined by spectrophotometry using glucose as a standard.

Biometric and quality results were subjected to analysis of variance. A regression analysis was performed, and the linear or quadratic coefficients were determined.

\section{Results and Discussion}

Cutting dates clearly influenced shoot growth, floral differentiation, and fruit yield of primocane-fruiting 'Autumn Bliss' red raspberry (Table 1). July cutting dates induced little variation in cane height and node count but a sharp decrease in leaf area and fruit yield from the second to the third date. This result shows that vegetative shoot growth is less affected than yield when cutting is delayed within July to induce a later harvest. When shoots were cut on 15 or 30 Aug., there was a substantial reduction in cane height, leaf area, and fruit yield in comparison with July cutting dates (Table 1). Cutting the shoots in August reduced shoot height by $33 \%$ to $40 \%$, fruiting node count by $58 \%$ to $67 \%$, leaf area by $72 \%$ to $94 \%$, and fruit yield by $92 \%$ to $97 \%$ compared to the first cutting date.

The August cuts delayed harvest until February and April, creating excellent marketing opportunities. However, this was done at the expense of plant growth and led to a poor fruit yield. It was clear that when shoots were cut too late in summer the decreasing temperature and solar radiation (Fig. 1) did not allow formation of sufficient vegetative growth to support an economic crop.

Air temperature inside the tunnel in July, August, and September was high, varying between 20 and 27 C. September to January was relatively cool, with the air mean varying between 12 and 20C (Fig. 1). In an open field, the air mean was $1.8 \mathrm{C}$ above average for 1967 to 1980 for July to September and $0.8 \mathrm{C}$ below average for September to January (Instituto Nacional de Meteorologia e Geofisica, 1991).

Inside the tunnel, PAR was $>800$ $\mu \mathrm{mol} \cdot \mathrm{m}^{-2} \cdot \mathrm{s}^{-1}$ from July to September. During October there was a sudden drop to $\approx 300$ $\mu \mathrm{mol} \cdot \mathrm{m}^{-2} \cdot \mathrm{s}^{-1}$ in November to January. In the open field, the number of hours of sunshine from September to January was less than average (Instituto Nacional de Meteorologia e Geofisica, 1991). Normally, the decrease in radiation would be less than experienced during November and December.

The number of days from shoot cutting to peak harvest was similar for the three cuts of July. However, the harvest delays were longer than the intervals between the shoot cutting dates for shoots cut in August (Fig. 2). Thus, early in the season, a certain delay in shoot cutting will correspond to the same delay in

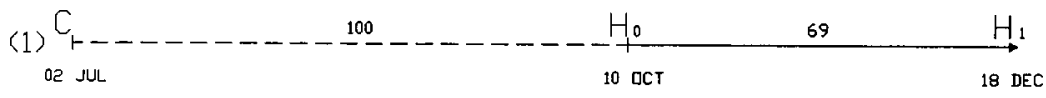

(2) $\mathrm{C}_{1}+\ldots$
$16 \mathrm{JUL}$
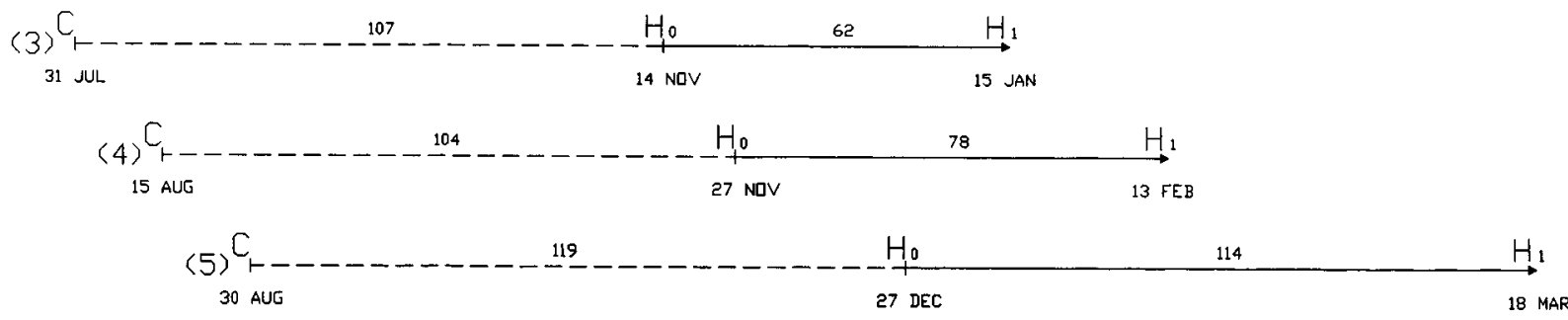

Fig. 2. Dates of cutting and number of days between cutting (C) and beginning of harvest (Ho) and peak of harvest (H1) for five cutting dates of 'Autumn Bliss' red raspberry. The numerals show the number of days between each date. Cutting dates: 1) 2 July, 2) 16 July, 3) 31 July, 4) 15 Aug., and 5 ) 30 Aug. 
fruit harvest. Although all July cuts induced cropping cycles of similar length, the accumulated temperature and PAR along the cropping cycle decreased considerably when shoot cutting was delayed (Table 2). The average daily PAR received by the plants was $31,29,26,23$, and $24 \mathrm{~mol} \cdot \mathrm{m}^{-2}$ for the five cutting dates of 2 July to 30 Aug., respectively. However, the plants cut on 30 Aug. received the highest accumulated PAR because of their longer cropping cycle (233 days). The lower PAR and temperature received by the plants of the later cuts associated with a smaller leaf area may explain the significant reduction in fruit yield.

July cutting dates did not affect fruit diameter, length, and weight (Table 3). Only SSC and reducing sugar concentration clearly decreased between the first and the third cutting date. Color improved with advancing July cuts since fruit of the second and third cuttings were more deeply colored than those of the first cutting date. Fruit with a relatively high SSC but dull color were characteristic of the first cutting date; the reverse was the case for the third date. However, all fruit reached sufficiently high quality standards when compared with fruit of the same cultivar produced in June to July in another experiment where fruit weight was $4.2 \mathrm{~g}$; SSC 7.0; and color 28.4,

Table 2. Effect of summer-cutting date on the length of the growth period of 'Autumn Bliss' red raspberry and the corresponding heat units $(\Sigma$ temp) and photosynthetic active radiation (PAR) $(\Sigma \mathrm{PAR})$.

\begin{tabular}{lccc}
\hline \hline $\begin{array}{l}\text { Cutting } \\
\text { date }\end{array}$ & $\begin{array}{c}\text { Growth } \\
\text { period } \\
(\text { days })^{2}\end{array}$ & $\begin{array}{c}\Sigma \text { temp } \\
\left({ }^{\circ} \mathrm{C}\right)\end{array}$ & $\begin{array}{c}\Sigma \text { PAR } \\
\left(\mathrm{mol}^{\circ} \mathrm{m}^{-2}\right)\end{array}$ \\
\hline 2 July & 169 & 2203 & 5263 \\
16 July & 164 & 2057 & 4719 \\
31 July & 169 & 1956 & 4306 \\
15 Aug. & 182 & 1773 & 4147 \\
30 Aug. & 233 & 1926 & 5490 \\
\hline
\end{tabular}

${ }^{2}$ From shoot cutting to peak harvest.

Table 3. Effect of the first three cutting dates on fruit quality of 'Autumn Bliss' red raspberry.

\begin{tabular}{|c|c|c|c|c|c|}
\hline \multirow[b]{2}{*}{ Variable } & \multicolumn{3}{|c|}{ Cutting date $^{2}$} & \multicolumn{2}{|c|}{ Significance } \\
\hline & 2 July & 16 July & 31 July & Linear & Quadratic \\
\hline$\overline{\text { Diameter }(\mathrm{cm})}$ & 2.0 & 2.0 & 1.9 & NS & NS \\
\hline Length (cm) & 1.9 & 1.9 & 1.9 & NS & NS \\
\hline Weight $(\mathrm{cm})$ & 3.8 & 4.1 & 3.6 & NS & NS \\
\hline $\mathrm{SSC}^{\mathrm{y}}$ & 8.5 & 8.1 & 8.1 & $* *$ & ** \\
\hline $\mathrm{pH}$ & 2.9 & 3.0 & 2.7 & NS & $*$ \\
\hline $\mathrm{TA}^{\mathrm{y}}(\mathrm{g} / 100 \mathrm{ml})$ & 1.5 & 1.6 & 1.4 & NS & NS \\
\hline $\operatorname{Sugar}(\mathrm{g} / 100 \mathrm{mg})$ & 5.3 & 3.4 & 2.1 & $* *$ & ** \\
\hline $\mathrm{L}^{*}$ & 23.3 & 27.0 & 27.8 & $* *$ & $* *$ \\
\hline $\mathrm{h}^{\text {oy }}$ & 16.5 & 20.6 & 20.8 & $*$ & NS \\
\hline $\mathrm{C}^{* \mathrm{y}}$ & 16.2 & 19.6 & 17.4 & NS & NS \\
\hline
\end{tabular}

${ }^{2}$ The fruit for analysis were sampled on 28 Nov., 13 Dec., and 16 Jan. for the cutting dates 2, 16, and 31 July, respectively.

${ }^{\mathrm{y}} \mathrm{SSC}=$ soluble solids concentration, $\mathrm{TA}=$ titrable acidity, $\mathrm{h}^{\circ}=$ hue angle $\left(\operatorname{arctangent} \mathrm{b}^{*} / \mathrm{a}^{*}\right) ; \mathrm{C}^{*}=$ chroma $\left\{\left[\left(a^{* 2}+b^{* 2}\right)^{1 / 2}\right]\right\}$.

Ns, ****Nonsignificant or significant at $P \leq 0.05$ or 0.01 , respectively. for production during the most unfavorable period. Under our experimental conditions, when summer-cutting is done before the end of July the productivity and quality of 'Autumn Bliss' are commercially acceptable and harvest is delayed by 3 months compared to a standard open-field crop. Further research on methods to improve photosynthetic leaf area index and to avoid excessive air temperatures inside the tunnels during summer are needed. Information on the accumulation and the partitioning of carbohydrates within the plant during the annual growth cycle also is needed for a better understanding of red raspberry performance under limiting conditions of temperature and PAR.

\section{Literature Cited}

Braun, J.W. and J.K.L. Garth. 1984. Intercane yield compensation in the red raspberry. J. Amer. Soc. Hort. Sci. 109:526-530.

Dale, A. 1989. Productivity in red raspberries. Hort. Rev. 11:185-228.

Dijkrtra, J. and A. Scholtens. 1993. Growing early and late raspberries in containers. Acta Hort. 352:49-54.

Faby, R. 1993. Extension of the raspberry season with cold treated plants. Acta Hort. 2:55-60.

Fernandez, G. and M. Pritts. 1994. Growth, carbon acquisition, and source-sink relationships in 'Titan' red raspberry. J. Amer. Soc. Hort. Sci. 119:1163-1168

Hoover, E., J. Luby, D. Bedford, M. Pritts, E. Hanson, A. Dale, and H. Daubeny. 1989. Temperature influence on harvest date and cane development of primocane-fruiting red raspberries. Acta Hort. 262:297-303.

Instituto Nacional de Meteorologia e Geofisica. 1991. O Clima de Portugal, Instituto de Meteorologia, Lisboa 49:57.

Lantin, B., A. Chavagnat, J. Maillet, and J. Laury. 1971. La culture de la framboise sous abris légers est-elle possible? Pépiniériste, Horticulteurs, Maraichéres 122:47-51.

Meesters, P. and F. Pitsioudis. 1993. Culture continue de framboise d'Été en conteneurs sous verre chauffé. Le Fruit Belge 454:59-62.

Oliveira, P.B. 1994. Influência da data de poda na produtividade da framboesa remo em estufa. MS Thesis, Technical Univ. of Lisbon, Portugal.

Oliveira, P., L. Lopes-da-Fonseca, and A. Monteiro. 1994. Influence of summer pruning on winter production of primocane-fruiting red raspberries under protected cultivation in mild winter climates. Acta Hort. 357:295-299.

Privé, J., J. Sullivan, J. Proctor, and O. Allen. 1993. Climate influences vegetative and reproductive components of primocane-fruiting red raspberry cultivars. J. Amer. Soc. Hort. Sci. 118: 393-399.

Williams, L.H. 1959. Effects of environment on Rubus idaeus L. IV. Flowering initiation and development of the inflorescence. J. Hort. Sci. 34:219-228.

Williams, L.H. 1960. Effects of environment on Rubus idaeus L. V. Dormancy and flowering of the mature shoot. J. Hort. Sci. 35:214-220. 